\title{
Assessing Key Factors in the Making Afan Oromo One of the Federal Working Languages
}

\author{
Wakgari Dulume \\ LL.B (Haramaya University), LL.M in Law and Development (Arsi University), Editorial committee member of \\ Oromia Law Journal
}

\begin{abstract}
In mosaic countries, choice of a language as lingua franka needs careful scrutiny; since language has more meaning than as a mare communication means. It is related with identity, cultural, political, social, and economic affairs of speakers. In Ethiopia, there are nearly 80 ethno-linguistic groups speaking their respective languages. In such scenario choosing one or more language as federal working language is difficult task. Ethiopia doesn't have a single policy document yet. However, the country has legally recognized only one language (Amharic) as federal working language. The choice of federal working language in Ethiopia seems arbitrary and also deviates from working language choice in multilingual states. The research is based on integrative literature review that synthesizes and critiques of secondary data. Objective principles for choice of working language; experiences three multilingual federal states having similarity with our country were reviewed. Based on these principles as well as experience countries, the finding claims Afan Oromo is not given the place it deserves in Ethiopia; which in fact is major causes for instabilities in the country. The article recommends Ethiopian government should make Afan Oromo additional federal working language as a part of responding to demands of Oromo people as well as a panacea for instabilities. Moreover, making it additional federal working language is reaching more population in the HoA which facilitate social integration.
\end{abstract}

Keywords: Afan Oromo, Federal Working Language, Horn of Africa, Language Policy

DOI: $10.7176 / \mathrm{IAGS} / 93-01$

Publication date: January $31^{\text {st }} 2022$

\section{Introduction}

The paper is organized into four sections including this succinct introduction. The second section is materials and methods that tell how the work is done. The third section is results and discussions. Under this section, issues like general conceptual framework of language policy; guidelines for selecting working language in mosaic countries like Ethiopia; experiences of some multi-lingual federation on working language choice having similarities with Ethiopian federation in terms of linguistic and cultural diversity to draw lesson(s) and fill the gap(s) of our current language policy [countries like: Nigeria, South Africa, and India]; analyzing Ethiopian language choosing for federal working language are discussed in detail. Finally, in the fourth section came up with summary of findings, conclusions and forwarded recommendations based on overall discussions.

Language is a term whose definition goes beyond a means of communication. It is an important instrument for the expression and transfer of cultural values, and is thus in most cases a distinctive feature of an ethnic group (Alemante, 1992:40). Moreover, it is important for an individual's feeling of self-worth as not respecting the language of a particular ethnic group (Alemante, 1992:41). Lahra Smith explained language being more than an instrument of good that allows us to communicate with each other (Lahra, 2007:212).Lahra related language with national identity having political, linguistic, educational, and aesthetic aspects. She says, "Language has an intrinsically valuable dimension which itself is a human creation or accomplishment, participation which is an end in itself" (Lahra, 2007). Hence, language has a direct link to cultural, political, social, and economic affairs of a certain country. Because of this, when governments come to power, making proper regulation on language should be one of the top agendas. One way of doing this is by having language policy; be it overtly written or covertly known (Getachew A. and Derib Ado, 2006:40).

Ethiopia has been regulating a language usage though not written in a single document called policy document since long years. Since the formation of Ethiopian empire, one language policy that made only Amharic the working language of the country has been in place. Such a language policy however is one of the contentious areas where scholars of the day do not have similar standing on it. Some appreciate it and argue for continuance of the present status quo. Some criticize it and propose to have two or more working languages for the federal government among which Afan Oromo is one. Still some others argue for the replacement of the present Amharic status with English.

Afan Oromo, the $3^{\text {rd }}$ largest and most widely spoken language in Africa (Dejene and Julia, 2013: 331), got minimal recognition in Ethiopia; in the country where the Oromos constitute almost half of Ethiopian population account for more than $34.40 \%$ of the population (World Fact Book, 2020). Afan Oromo is spoken by the Oromos, largest ethnic group in Ethiopia. Afan Oromo is a working language in Oromia regional state (Revised Oromia Regional State Constitution Article 5) Oromia is one of the regions establishing Ethiopia that contributed a huge 
land area and population to Ethiopia. Afan Oromo is a member of Afro-Asiatic language family and Cushitic language spoken by about 50 million people in Ethiopia, Kenya, Somalia, Egypt and other countries (Ibrahim, 2015: 52).Within Ethiopia, Afaan Oromo is spoken in different regions. For instance, in Harari regional government, both Hararii and Afaan Oromo are working language. In Benushangul Gumuz, particularly in Matakal Wambara, majority speaks Afan Oromo and yet they were not given a chance to teach their children in their mother tongue (Afan Oromo). In Somali region too Afan Oromo is -spoken. Observing these facts, it is absurd why Afaan Oromo isn't yet recognized as the federal working language in Ethiopia.

Language is often seen as a vehicle to help achievement of unity; hence it has a view that language is a unifying factor (Tom Guldemann, 2015:309). Tom disproved the assertion and views that multilingualism is divisive and mono legalism is unifying. Observing the mono lingual countries like Rwanda and Somalia where conflict is prevalent concluded that speaking one language could not be unifying factor. The researcher also argues multilingualism rather have unifying factor in multilingual countries such as Ethiopia like most of Oromo scholars such as. Birhenmeskel Abebe, Aberra Degefa, Tsegay Ararsa, Milkessa Midhaga. According to (Birhanemeskel, 2015), Ethiopia is the only country in which the government of the country refused to speak the language of the majority of its people raising the case of Afan Oromo. He said, such act has negative effect on unity of the country and urged the federal government to make 'Afan Oromo legally and unconditionally the working language of the federal government'. The Oromos that accounts for $34.40 \%$ of Ethiopian population is sidelined from educating their children in Afan Oromo, both as a subject and as a medium of instruction irrespective of levels and types of disciplines and subsequently and/or consequently taking job opportunities at federal level as non-Amharic speakers could not be employed. Oromo youth cannot take part in federal structure because federal do not speak their language and this highly affects even economic development of the country since the country cannot unitize intellectual mind of non-Amharic speaking. Most importantly, among the centre of politics of the Oromos, that account for almost half of Ethiopian population one is making Afan Oromo federal working language. Negative answer to such question has huge economic, social, cultural and political consequences.

\section{Material and Methods}

The paper has attempted to make an appropriate review of the existing literature on language policy and factors considered in the choice of a language as working language in mosaic countries. Laws, books, journal articles and materials from internet sources are used. The research is based on literature review. Particularly, it is based on the integrative literature review; where critiques and synthesis of secondary data sources are made. This type of literature reviews the appropriate; since the research does not involve in analysis of primary data. To achieve its objective, extensive literature in context is made.

History of language usage in Ethiopia from Imperial time till now is scrutinized. Internationally accepted guideline to choice working language in multilingual countries is reviewed and whether Afan Oromo deserve recognitions of federal working language based on these guidelines is evaluated. Moreover, experiences of some multi-lingual countries having similarity with the Ethiopian federal system is assessed to know key factors to judge whether making Afan Oromo federal working language is appropriate or not. Accordingly, experiences multi-lingual countries such as: Nigeria, South Africa and India on the choice of federal working language are assessed with the view to take lesson from them.

\section{Results and Discussions}

\subsection{Language Policy: Conceptual Framework}

One cannot get a universally accepted single definition of language policy. Different authors defined the term differently. However, in most cases, the definitions are either of general or specific nature. Among the authors who gave general definitions, as Schiffman, 2005, language policy is all about "decisions, rules, regulations, and guidelines about the status, use, domains, and territories of language and the rights of the speakers under question". Similarly, (Calvert, 1998) understands language policy as "the conscious choice made in the domain of relationship between language and social life as a whole". Both definitions are very general, in that, they only tell us the decisions and choice of language in relation to its speakers or society in general. One cannot, for example, grasp from the definitions as to who makes the decision or choice, and how the decision or choice is to be made. follows:

On the other hand, Crawford, 2000:180), tried to give specific definition to the term. He defines it as

Language policy is what government does officially through legislation, court decisions, executive action or other means to determine how languages are used in public contexts, cultivate language skills needed to national priorities; or establish the rights of individuals or groups to learn, use, and maintain language.

He further goes on defining the term as, government regulation of its own language including steps to 
facilitate clear communication, train and recruit personnel, guarantee due process, foster political participation, and provides access to public services, proceedings and documents (Crawford, 2000). Be it general or specific, what one can deduce from the above definitions is that language policy is a purposive decision or choice made authoritatively by the government as to the domain of application and its sustained developments of certain language(s).

The issue of adopting one or more official languages is on the thorny point in multicultural federations. Regional and ethno-linguistic groups usually press for the official recognition of their languages, both at regional and federal levels. One reason is that language is seen as highly related to the cultural self-identity, and survival of groups (Ronald Watts, 1966). Another is that, it is intertwined with the power position of ethnic groups. To a certain degree it affects access to national jobs and therefore the participation of members of ethno-linguistic minorities at the center (Ronald Watts, 1966:233). The adoption of more than one official languages may be a substantial burden, but it is a necessary price, which must be paid where otherwise only an imposed single language is likely to disrupt the state (Ronald Watts, 1966:32). The counterargument is that a single national language serves both as lingua franca and as a means for promoting national unity. However, multi-lingual federations often adopted either of the two approaches at federal level to settle the issue of official language. This could be observed from Indian constitution (2010) Articles 343, 345 and the eighth Schedule. One can also observe from the Swiss Constitution (2014) that provided for three official languages.

To avoid arbitrary selection of one or more languages as official language in multilingual and multicultural state, Capotorti (1996:75) as in the works of (Aberra, 2009:90) identified certain guideline(s). Let's see these guidelines very briefly.

\section{i) Sliding-scale Approach}

According to this guideline, the numerical size of the speakers of a certain language in proportion to the general population of a country is one of the very important factors that have to be taken into account in the selection of working language (Aberra, 2009:Ibid). This approach impose states obligation towards the language speakers go from the largest to the smallest in a descending order(Aberra, 2009:91). This implies that it will be unfair if state does not provide public services in a given language as per the size of the speakers of the language.

\section{ii) Economic and Political Position}

Where there are a number of linguistic groups competing for the status of working language, along with the numerical size, the economic and political position of the speakers of the language communities has to be taken into account in making the choice (Aberra, 2009:92).Accordingly, the number of speakers of a certain language have to be given a position that more or less corresponds to their economic and political position in the country.

\section{iii) Neutrality}

Where two or more languages are competing for the status of official working language "a neutral language that is not associated with a particular power" is preferred as the working language over the others (Aberra, 2009:95). If it is not neutral, it is often regarded as a tool by which a particular language group seeks to extend its domination. For example, there are African states that decided to make a single major European language like English and French the national working languages and their indigenous local languages to be used equally to their respective areas. (In what context this neutrality works? Please state in detail about this if raised in this work. I wonder if we can truly find such single state practicing it in that for language and culture have been married not to be divorced I know.) In nutshell, choice of the working language in multilingual society is said to be balancing competing interests if it is guided by the above guidelines.

\subsection{Language Policy: Experiences of Certain Multilingual Federations}

In this section, we are going to see experiences of language policies of some multilingual federations having similarities in terms of their linguistic and cultural diversity to Ethiopian federation. These federations are both from within African continent and outside of the continent. The aim is to draw lesson from these federations and fill the gap(s) of our current language policy. The selected countries are Nigeria, and South Africa from African continent; and India from Asian continent.

\subsubsection{Nigeria}

Nigeria is one of the ethno-linguistically diverse African countries, mainly because of its colonial legacy (Fiseha, 2014).The nation was formed in 1914 by merging the three West African British Protectorates. It is believed that around 400 languages are spoken in Nigeria (Fiseha, Ibid). The language policy of the country can be seen by categorizing into two durations; the time before independence and after independence.

Before independence, i.e., 1960, English was the major language used in spheres of education. After independence; however, multilingualism was recognized to the extent of identifying official language and national language. National language and official language are the two confusing concepts which are used mainly in multilingual countries although FDRE Constitution employed neither of them. They are two different concepts and using them interchangeably is committing an error. A good way to understand their difference is considering their features. A national language is a language that a country uses to reflect its collective identity 
to the world at large; it is the language spoken by majority of the population of a country in which the government corresponds with international organizations such as UN and other countries. Official language, on the other hand, is the language patronized by the administration and used widely, not just for communication but also for correspondence. It is the language in which the government conducts its business and therefore carries far more political and legal significance (Oliva, 2006). Accordingly, English became official language and the other three languages spoken by the three dominant ethnic groups (Yorba, Igbo, and Hausa) became national languages (Fiseha, 2014). Other languages were used by the concerned community at the regional and local level. The reason for adopting English as an official language was a lack of agreement among the speakers of the three widely spoken Nigerian languages. On the other hand, the three languages were introduced in an effort to create a sense of national cohesion by encouraging linguistic convergence along the widely spoken languages. A lesson that can be drown from the experience of Nigeria is that, Afan Oromo the widely spoken language having largest number of speakers as mother tongue in the country Ethiopia which is also spoken in almost all Horn of African countries and in some of East African countries deserves, at least, recognition of federal working language and at most break about four GADA's(i.e. over three decades) stagnation of Afan Oromo Education at grade eight(8)take action to practice the Additive language use system in Ethiopia.

\subsubsection{South Africa}

South Africa is the other African country where linguistic diversity is observable. The current language policy of South Africa is a redress to injustices of Apartheid; where English \& Afrikaans were given higher status at the expense of other languages prior to 1994 (Baba P, 2013). The constitution of South Africa also clearly imposes obligation upon state by stipulating that it must take positive measures to elevate the status and advance the use of indigenous languages of South Africa (Russel H.Kaschula, 2004). This could understand from the reading of section 6(2) of the South African Constitution (1998). Accordingly, this constitution has several other sections governing language issues.

For example, see section 6(3)\&(4) which obliges government departments at national and provincial to use at least two of the official languages; section 9(3) which protects against unfair discrimination on the ground of language; and Section 35 (3) and (4) which ensures the language rights of the arrested, detained and accused persons with particular emphasis on the right to a fair trial with proceedings conducted or interpreted in the language of that individual's choice can be cited in this regard. One important measure taken by the government in this context is that of declaring 11 languages as official languages in 1994.The 11 languages given the official status were the following (Russel H. Kaschula, 2004):

\begin{tabular}{|l|l|l|}
\hline No & Language & Number of speakers \\
\hline 1 & isiZulu & $24 \%$ \\
\hline 2 & isiXhosa & $18 \%$ \\
\hline 3 & Afrikaans & $14 \%$ \\
\hline 4 & Sepedi & $9 \%$ \\
\hline 5 & English. & $9 \%$ \\
\hline 6 & Sesotho & $8 \%$ \\
\hline 7 & Setswana. & $8 \%$ \\
\hline 8 & Xitsonga & $4 \%$ \\
\hline 9 & siSwati & $2 \%$ \\
\hline 10 & Tshivenda. & $2 \%$ \\
\hline 11 & isiNedebele & $1 \%$ \\
\hline
\end{tabular}

The purpose of giving these languages official status was to promote African languages which were neglected in the past (Baba P, 2013). Provinces were also free to choose their own regional official language (Baba P, 2013). For its implementation and further development of linguistic diversity, the constitution established the Pan South African Language Board which works in collaboration with other role players like Department of Art and Culture (Russel H. Kaschula, 2004).

In general, South Africa has a language policy that promotes multilingualism both at national and provincial levels. In fact, it is clear that such types of policy demands allocation of both human and physical resources. But redeeming historical injustice done to African language through such language policy is good.

Similarly, everybody knows historical injustice done to Afaan Oromo and other languages spoken in Ethiopia during and after formation of Ethiopian empire; even until now that urges for redemption thoroughly. One mechanism of redeeming such historical injustice done to Afan Oromo could be by giving recognition it deserve which includes making it federal working language, at least then open an opportunity for the paving of the way to the true and sustained freedom in applying unrestricted Afan Oromo education policy, for if the best tool (Mother tongue as a medium of instruction and trainings, that could produce effective working spheres) for quality education fails, everything good could not be expected. And forgetting not the technical and commitment challenges, Afan Oromo have greater potential in terms of appropriate words than those new and constitutionally 
recognized 9 official languages (i.e. excluding English and Afrikaans).

Prof Wolff stated by referring Alexander (2003) in his public lecture that, “... The failure of post-colonial African states to base their educational systems on the home languages or at the very least on the languages of the immediate community of the child, more than any other policy or practice, explains the fundamental mediocrity of intellectual production on the continent, including South Africa."

\subsubsection{India}

India is one of the multilingual nations in the world (Jason Baldrige, 1996). Like Nigerian language policy history, the language policy history of India could be considered by taking into account the time before and after independence. Before independence, English was used as the principal language of administration both at the national level and in the regions. Having attained independence from the British in 1949, Indian leaders recognized the opportunity to unite the many units of India with a common, universal language (Ibid)). Setting criteria for making a certain language a national language became one of the priority issues for Mahatma Gahandi. Accordingly, he pointed out five requirements for any language to be accepted as the national language:

1. It should be easy to learn for government officials;

2. It should be capable of serving as a medium of religious, economic and political intercourse throughout India;

3. It should be the speech of the majority of the inhabitants of India;

4. It should be easy to learn for the whole of the country;

5. In choosing this language, considerations of temporary or passing interests should not account (Ibid).

The post-colonial language policy development of India faced two competing interests. On one hand, when India's focus on technology and education for economic benefit, the colonial language, i.e., English was more preferable than other languages. On the other hand, India has the most extensive representation of multiculturalism of any nation as members of different tribes, castes, races, and religions which call for the use of indigenous languages. The attitude toward the English language was also not uniform among Indians. Some Indians perceive it as a "symbol of slavery" considering it as a colonial language; others perceive it as a way to gain mobility and benefit (Ibid). Passing through these all contentious language policy issues, Indians have chosen Hindi and English as their official language. In addition to this, the Indian system recognizes twenty two state languages (Yonatan, 2009).

In general, two lessons of language policy could be drawn from the experiences of the above federations at the national level. First, all of them use more than one language at the national level. Second, their concern to make indigenous languages official is very high. In all the three federations, English became official language not because they were interested to make it official; rather the existing situation compelled them.

As stated in the Indian Education Policy at large and specifically pointed out related to Multilingual Mother Tongue Education: "UNESCO is developing a number of initiatives for the promotion of mother tongue instruction and multilingual education to enhance the quality of education." At the same time UNESCO also "... supports bilingual and/or multilingual education at all levels of education as a means of promoting both social and gender equality and as a key element of linguistically diverse societies." Regarding policies: "The best policies are those that establish multilingual education as an integral part of formal and informal education and gives clear directives for its implementations." Thus, from these contextual passages and those related reviews above, a lot could be considered as an input would be fair policies creation here in the new home land.

\subsection{Language Policy of Ethiopia}

Language policy in Ethiopia is akin to long history of the country. In this short article, time and space will not allow to exhaustively trace back what language policy of the country look like throughout history. However, it is good to make a glance to overview of language policy from its modern history; Tewodros II (1855 - present). It is good to dived this time into two; from Tewodros-transitional period and after the 1995 FDRE Constitution. The writer preferred this way of arrangement as the transitional period was the time when the greatest departure was made regarding language policy of the country's modern history.

\subsubsection{From Emperor Tewodros II to Transitional Government Charter (1855-1991)}

This period is more than a century as it covers the reigns of Tewodros II, Yohannes IV, Minilek II, Haile Silassie I, and Dergue who ruled the country in their chronological order. They all made Amharic lingua franca. The first three emperors were known for the attempt to unify Ethiopia; which is finalized by Minelik II. According to (Alemseged, 2004), their language policy was promoter one as they encourage and even force others to use Amharic language. Haile Silassie I introduced assimilation policy to homogenize Ethiopian society effectively and language was used as a crucial tool for implementation. Amharic became the national/official medium of the country and non-Amhara Ethiopians were obliged to study it (Alemseged, 2004).Outside of the official arena, too, people were directly and indirectly encouraged to abandon their own mother tongues in favor of Amharic. This can be witnessed by the speech the Emperor made to Eritreans during his extensive visit in 1955. He 
impressed upon the people that they had to study Amharic, which he claimed as international language unlike Arabic which was trying to compete with local language, Tigrenya, as a lingua franca of the region (Alemseged, 2004). But in the Degue system, there was a different move in the language education, in that 14 other Ethiopian languages were considered by the Government in applying for the basic education for all campaign, a very EALY EXIT language education approach. It was less favoring for the local languages' functional opportunities creation than the current LATE EXIT language education approach. But there was no opportunity to education and promotion to working areas except in Amharic and other foreign languages.

\subsubsection{From 1991 to the Present}

Ethiopian People's Revolutionary Democratic Front (EPRDF) government made efforts institutionally reflecting the country's diversity in so many ways; of which language was one (Yared, 1999).Different measures such as drafting education policy statement on language which provided on the use of nationality languages, specifically identifying Amharic, Oromo, Tigre, Wolayta, and Sidama; translation of text books [1993]; publishing National Education and Training Policy with the objectives of recognizing the rights of nations/nationalities to learn in their own language, while at the same time providing one language for national and another one for international communication were taken with regard to language during transitional period from recognizing different languages for education to large scale interpretations as well as publishing national education and training policy. Under the 1995 FDRE Constitution, language has been a pivotal dimension of ethnic federalism in Ethiopia. Excluding Art.46 (2) which made language a criteria for delimiting federating units, the relevant provisions governing language under the FDRE Constitution are Article 5 and 39(2). The full texts of these provisions are reproduced as follows:

\section{Art.5: Languages}

All Ethiopian Languages shall enjoy equal state recognition.

Amharic shall be the working language of the federal government.

Members of the federation may by law determine their respective working languages. Art. 39(2):

Every Nation, Nationality, and People in Ethiopia has the right to speak, to write and to develop its own language; to express, to develop and to promote its culture; and to preserve its history.

As all indigenous Ethiopian languages enjoy equal state recognition, nations, nationalities and peoples are at liberty to speak, to write, and to develop their own language.

However, the constitution made only Amharic the working language of the federal government and authorized members of the federating units to determine their respective working language by law. And still there is no policy to sustain quality mother tongue education at all levels and subsequent working condition throughout the country in harmony except in Amharic and other foreign languages.

The issue to be examined here is, whether or not the choice of Amharic only as the working language of the federal government was proper in multilingual country, Ethiopia based on internationally accepted guidelines. As discussed in the first section, there are internationally accepted guidelines based on which official/national working language is selected. Thus, the researcher evaluate whether Afaan Oromo deserve recognition of federal working language based these accepted guidelines.

\section{a) Sliding-Scale Approach}

This approach considers numerical size of the speakers of a certain language in proportion to the general population of a country as important factors to select a language as working language. Sliding-scale approach asks state to treat languages according to numbers of speakers in descending order. According to the 1994 census, the total population of Ethiopia was 53,132,276 (CSA, 1994). Out of this, Oromos, Amharas, Tigrians, Guraghes, and Somali constitute the largest five ethnic groups. Ethnically, the Oromos constitute the largest group in Ethiopia; but with lower number of Afaan Oromo speakers when compared to Amharic speaker. This can be illustrated as follows:

\begin{tabular}{|l|l|l|l|}
\hline Language & $\begin{array}{l}\text { Number of people speaking as } \\
\text { mother tongue }\end{array}$ & $\begin{array}{l}\text { Number of people speaking as } \\
\text { second language }\end{array}$ & Summation \\
\hline Afaan Oromo & $31.6 \%$ & $2.91 \%$ & $31.6 \%+2.91 \%=34.5 \%{ }^{1}$ \\
\hline Amharic & $32.7 \%$ & $9.61 \%$ & $32.7 \%+9.61 \%=42.31 \%$ \\
\hline Tigiregna & $6.07 \%$ & & \\
\hline
\end{tabular}

Source: CSA, 1994)

From the above table, one can read that Amharic has greater number of speakers both as mother tongue and second language followed by Afaan Oromo from the then total population of the country. Because of this, based

${ }^{1}$ The 1994 population and Housing census of Ethiopia, Office of Population and Housing Census Commission, Volume II, Analytical Report, Central Statistical Authority, Addis Ababa, November 1998 as cited in AberraDegefa, Principles Guiding the Choice of Working Languages in Multilingual Societies: Some Reflections on the Language Policy of Ethiopia,P106. The most recent census report, 2007 did not listed number of speakers and that is why the 1994 census data was used. In both 1994 and 2007 census report ethnic Oromo are large in number and even Afaan Oromo is the $4^{\text {th }}$ most spoken in Africa even though Amharic speaker in Ethiopia has slight larger numbers. 
on the sliding-scale approach making Amharic the federal working language is appropriate. However, in multilingual federations, it is uncommon to make only one language a federal working language as observed from the above experiences in many countries located here in Africa and Asia, for instance. In addition to that, even according to guidelines developed by Capotorti, considering only sliding-scale approach is not enough for choosing working language. Considering other guidelines is equally important making Afaan Oromo deserve federal working language recognition.

b) Economic and Political Position

When viewed from political and economic importance of the speakers of the language, both Oromo and Amhara can be placed at comparable size because of their respective wider number of speakers and their natural resources. For example, in the House of People's Representative of the FDRE, out of 547 seats in the House, Oromo People Democratic Organization (OPDO/ODP) had 178 seats; whereas the corresponding Amhara Nation Democratic Movement (ANDM/ADP) had 138 seats. This figure shows the political importance of Oromos in decision making. When viewed from economic point of view, the contribution of Oromos and the region to national economy is also of paramount importance because of availability of natural resource and number of population. In this regard, even the balance of choice tilts toward Afaan Oromoif a fair consideration employed for selection of federal working language.

Moreover, Afan Oromo is mother tongue for $34.5 \%$ of Ethiopian population that makes it the largest mother tongue spoken in the country; followed by Amharic which is spoken by $26.9 \%$, according to a 2007 report by the Central Statistic Authority (CSA, 2007). Among languages spoken in Ethiopia, Afaan Oromo is first language spoken outside of the country Ethiopia making it the $3^{\text {rd }}$ most widely spoken language in Africa. Sidling this language amounts to sidling $34.5 \%$ of Ethiopian population from economic contribution that may be generated from federal government. This sidling has direct effect on economic contribution of its speakers to the country's GDP particularly from federal organization. This problem is revealed by (Aberra, 2008) obtaining statistical data from the Federal Civil Service Agency in 2000. Accordingly, the percentage of Amharas in the Federal Civil Service accounts for $46.85 \%$ while that of Oromos and Tigrians account for $17.42 \%$ and $6.69 \%$ respectively indicating that the existing language policy maintained the dominance of Amharic speakers. This shows not only negative aspect to economy due to language policy but also its deviation from the accepted guidelines in making certain language a working language; and this can be taken as one challenge of the current Ethiopian language policy.

c) Neutrality

As to this standard, neither Afan Oromo nor Amharic is politically neutral. Both languages are indigenous and have cultural and political affiliation. So, this standard cannot help us for prioritizing Afan Oromo to Amharic or Amharic to Afan Oromo.

d) The Degree of Relation to other Local Languages

The other standard upon which a certain language is preferred is that the language to be preferred has to be linguistically related to the various local languages. In this regard, if we compare the numerical size of the major Cushitic groups and Semitic groups, they come out as follows, [taken from the 1994 census].

Cush Family

Oromos

Sidama

Somali

$$
\begin{gathered}
\text { Population } \\
17,080,318 \\
1,842,314 \\
3,160,540
\end{gathered}
$$

\section{Percent \\ 32.13 \\ 3.47

\begin{tabular}{|c|c|c|}
\hline & Population & Percent \\
\hline Amhara & $16,007,933$ & 30.13 \\
\hline Tigray & $3,284,568$ & 6.18 \\
\hline Gurage & $2,290,274$ & 4.31 \\
\hline & $21,582,775$ & 40.62 \\
\hline
\end{tabular} \\ 5.95}

Total 22,083,172 $\quad 41.55$

The corresponding numerical size for the Semitic group is,

It is evident from the given figures that Cushitic language group by itself constitutes more than 41 percent of the total population of Ethiopia. With the Omotic and Nilo-Saharan ${ }^{1}$ groups they are going to account for about 60 percent of the total population. Both these major language groups are not linguistically related to the Semitic language group. In this regard, again, Afan Oromo deserves federal working language recognition on par with Amharic even preferred to Amharic in the aforementioned principles.

\footnotetext{
${ }^{1}$ This is so because all languages in Ethiopia can be classified into 4 linguistic families. Namely, Semetic, Cushitic, Omotic and Nilosaharan(see Lahra Smith, P215).
} 


\section{e) National Unity, Modernity, and Technological Advance}

In these cases, although contribution of both languages, for that matter any language, is not underestimated, the contribution is not bold enough to make either Afan Oromo or Amharic the federal working language. This is because, although Amharic was the main language used as a tool during assimilation policy, it was not succeeded as it created domination of a single ethnic group thereby providing no long-term stability in the country (Berma, 1999). On the other hand, since Afan Oromo was not given a similar chance to Amharic, it is difficult to judge its contribution in this regard. Recently however, following PM Dr. Abiy coming to power; effort has been made to national unity. More importantly, it not only is limited to national unity, but better to consider regional integration which is the motto of the current time. If this is to be promoted, particularly, in East Africa and HoA, working in Afaan Oromo is crucial. The Oromos have been raising question of making Afaan Oromo federal working language; and failing to respond to this question has dragged Oromos off national unity. Since Dr. Abiy's coming to power, the Oromos are hoping he will make the language federal working language, and strengthen more national unity of the country that seems better now a day.

Generally, when evaluated from the international guidelines for choosing the working language, the present working language policy of federal government has problem as it failed to consider other competing languages on par with Amharic; Afaan Oromo is the case in point. Hence, argument of some scholars like Dr. Gheladews for maintaining the present status quo does not hold water as there are no any logical reasons that make Amharic and Amharic only as the working language of the federal government.

\section{Summary of finding, Conclusion and Recommendations}

Based on the overall discussions so far made the following summary of findings, conclusions and recommendations can be drawn.

\subsection{Summary of Finding}

The importance of language in human society is enormous. Citizens cannot receive any services of political goods from government without a language. Because of this, governments want to have language policy either overtly written or covertly known. Language policy generally refers as to decisions, rules, regulations, and guidelines about the status, use, domains, and territories of language and the rights of the speakers under question. In multilingual societies it is difficult to choose certain language as working language. The difficulty arises because of compromising the language rights of citizens and the interests of the state. To mitigate this difficulty, scholars like Capotorti, developed guidelines for choosing working language:

$>$ Sliding-scale approach

$>$ Economic and Political Position

$>$ Neutrality

$>$ The degree of relation to other local languages and

$>$ Maintaining national unity, modernity, and technological advance

From the modern history of Ethiopia, its language policy did not follow these guidelines; and one language (Amharic) is unduly favored to be official and national language since Tewodros II. From the transitional government (1991 to the present time), there is a little departure with regard to language policy at least recognizing other languages at regional and local level. The 1995 Constitution guaranteed equal recognition of all Ethiopian languages; however made Amharic the only working language of the federal government. Thus, it is vivid that the large populations (over $50 \%$ of the Afan Oromo skilled people-including the increased Afan Oromo as L2 communities) of the country have no legal access and job opportunities to use its language.

\subsection{Conclusions}

This paper examined whether Afaan Oromo meets internationally accepted guidelines to be chosen as federal working language. To this end, a concluding affirmative answer to the question has been obtained. However, makers of FDRE Constitution are reluctant to consider it. They failed to appreciate the other equally competing language, [Afaan Oromo] and ignored the cardinal rule of proportionality in ethno-linguistic democracy. As a result, a question of the Oromos that accounts for over $40 \%$ and over $10 \%$ of Afaan Oromo as skilled citizens and/or communities of Ethiopian population remained unanswered. This has, in its part sustenance of social, economic and political problems to the country. Though the issues of the region widely sustained numbers of protests in the past two years was not only to make Afan Oromo the federal working language, it is one and key questions of Oromos for decades. Unless this question is answered which of course a legitimate question, it is inevitable that the history of over two years sustained protects that resulted in economic problem due to insecurity that caused "FDI" reduction is going to repeat itself.

Based on guidelines such as economic and political position as well as national unity even regionally, which is hailed by PM Dr. Abiy, Afaan Oromo deserves recognition as federal working language. Moreover, experiences of different multi-lingual federations show commonness of choosing more than one language as 
federal working language. In this regard, Ethiopia can draw lesson from India, Nigeria, and South Africa. Hence, the paper concludes that the present federal working language demands a quick reform and pertinent development works so as to add values on the incumbent reforms of the country.

\subsection{Recommendations}

To answer a key question of over 40 million of the Oromo people and other potential use of Afan Oromo:

$>$ Oromia National Regional State Government has to take visible measure to make Afan Oromo federal working language and take back up to ensure effective sustainability of opportunities for the future generation through setting additive language education policy in its context.

$>$ The makers of constitution have to work on the amendment of Article 5(2) of the FDRE Constitution adding Afaan Oromo to federal working language. Owing rigidity of amending Ethiopian constitution, enacting a proclamation or language policy document declaring Afaan Oromo as a federal working language could be other alternative to respond to a question of the Oromo people, the largest ethnic group of Ethiopian federating units.

$>$ Scholars in the field are advised to conduct more research so as to influence government respond a question of millions of Oromos by making Afaan Oromo federal working language.

$>$ In a country like Ethiopia where cultural, language, religious diversity is prevalent, mutual respect for each other's language, culture and religion is of greater importance. Thus, both speakers and nonspeakers of Afan Oromo are advised to uphold one another's language and join the campaign to make Afan Oromo as one of additional federal working language.

\section{References}

Alemante G.Selassie (1992), Ethnic Identity \&Constitutional Design for Africa, Stanford Journal of International Law, Vol. 29 (1)

Ibrahim Badane (2015), The Origin of Afaan Oromo: Mother Language. available at https://scholar.harvard.edu/files/erena/files/the-origin-of-afaan_oromo.pdf.

Lahra Smith (2007), the Politics of Contemporary Language Policy in Ethiopia, Journal of Development Studies, Georgetown University, http://jds.sagepub.com/.

Getachew A. and DeribAdo (September 2006), Language Policy in Ethiopia, Ethiopian Journal of Education \&Science, Vol.2, No 1

SchiffmanHarod, Language Policy, Introductory Remarks, (2005) http://ccat.sas

Calvet,L-J, Language Wars and Linguistics Politics(1998): Oxford, Oxford University Translated by Michel Petheram.

Crowford,J.W,Language Policy (2000), http://ourworld. Compuserve /homepages /JWCrawford /langpol.htm

Ronald Watts, New Federations: Experiments in the Common Wealth (Oxford: Clarendon Press, 1966).

AberraDegefa, Principles Guiding the Choice of Working Languages in Multi-Lingual Societies: Some Reflections on the Language Policy of Ethiopia, Ethiopian Constitutional Law Series No 2, 2009.

Oliva, Difference between Official Language and National Language, available at http://www.deferencebetween.com/official-language-and-vs-national-language retrieved on 3/20/2019.

FisehaHaftetsion, What Languages Should Ethiopians Speak? http://Africanidea.org /what language_ ethiopians speak.htm.

Dr. Baba P. Tshotsho, Mother Tongue Debate and Language Policy in South Africa, International Journal of Humanities and Social Science, Vol.3, no 13, July 2013,University of Forte Hare.

RusselH.Kaschula (2004), South Africa's National Language Policy Revisited: The Challenge of Implementation.

Jason Baldrige, Reconciling Linguistic Diversity: The History and Future of Language Policy in India, University of Toledo, August 1996.

Yonatan Tesfaye, a Tale of Two Federations: Comparing Language Rights Regimes in South Africa and Ethiopia, Ethiopian Constitutional Law Series, Vol.2, 2009.

AlemsegedAbbay, Diversity \& State Building in Ethiopia, African Affairs, Royal African Society, 2004.

YaredLegesse, Linguistic Regimes in Multinational Federations: The Ethiopian Experience in A comparative Perspective, Ethiopian Constitutional Law Series, Vol.2, 1999 (Addis Ababa University)

The 1994 population and Housing census of Ethiopia, Office of Population and Housing Census Commission, Volume II, Analytical Report, Central Statistical Authority, Addis Ababa, November 1998.

FDRE Population Census Commission (2008), Summary and Statistical Report of the 2007 Population and Housing Census Results.

AberraDegefa (2008), Language Choice in multilingual Societies: An Appraisal of Ethiopian Case, Journal of Oromo Studies, Vol.15, No 2.

Berma Klein Goldewijk and Bas de GaayFoertman, Where Needs Meet Rights, WCC Publications, Geneva, 1999. 
Tom OnditiLuoch (2015), The Myth of Language as a Unifying Factor Conflict in Monolingual Rwanda and Somalia.

Birhanemeskel Abebe Segni (2015), 10 Reasons why Afaan Oromo should be a federal working language, https://hornaffairs.com/2015/03/01/afaan-oromoo-be-federal-working-language

Dejene Geshe, Julia Devardhi (2013), assimilation in Oromo Phonology, available at Language in India www.languageinindia.com. 